\title{
ELECTROMAGNETIC COMPATIBILITY OF A DC POWER DISTRIBUTION SYSTEM FOR THE ATLAS LIQUID ARGON CALORIMETER
}

\section{COMPATIBILIDAD ELECTROMAGNÉTICA EN EL SISTEMA DE DISTRIBUCIÓN DE CORRIENTE CONTINUA PARA EL CALORÍMETRO DE ARGÓN LÍQUIDO EN ATLAS}

\author{
George Blanchot $^{1}$ Luis Hervas ${ }^{1} \quad$ Jim Kierstead $^{2} \quad$ Francesco Lanni $^{2} \quad$ Sergio Rescia $^{2}$ \\ Mauricio Verdugo ${ }^{3} \quad$ Jorge Pontt $^{3} \quad$ Ricardo Olivares $^{3} \quad$ Hernán Robles $^{3} \quad$ Sergio Díaz $^{3}$
}

Recibido el 22 de agosto de 2007, aceptado el 27 de septiembre de 2007

Received: August 22, 2007 Accepted: September 27, 2007

\begin{abstract}
RESUMEN
El Calorímetro de Argón Líquido en ATLAS es alimentado por convertidores DC/DC localizados cerca de sus compartimientos. Ellos son alimentados por convertidores AC/DC localizados en una sala de control lejana conectados mediante cables largos de poder. La estabilidad del sistema de distribución es sensible a la impedancia del cable largo de interconexión y son requeridos los convertidores apropiados para estabilizar la dinámica de la impedancia. También, el cable largo alimentado por el convertidor AC/DC es una fuente de interferencia electromagnética en el área experimental. En este trabajo se analiza la óptima configuración de aterrizamiento y blindaje para minimizar los efectos de EMI.
\end{abstract}

Palabras clave: Compatibilidad electromagnética, sistema de distribución de corriente continua, estabilidad, propagación de ruido, emisiones de interferencia electromagnética.

\section{ABSTRACT}

The front-end electronics of the ATLAS Liquid Argon Calorimeter is powered by DC/DC converters nearby the front-end crates. They are fed by AC/DC converters located in a remote control room through long power cables. The stability of the power distribution scheme is compromised by the impedance of the long interconnection cable, and proper matching of the converters dynamic impedances is required. Also, the long power cable fed by a powerful AC/DC converter is a source of electromagnetic interferences in the experimental area. The optimal grounding and shielding configuration to minimize these EMI is discussed.

Keywords: Electromagnetic compatibility, DC power distribution system, stability, noise propagation, EMI emissions.

\section{INTRODUCTION}

The term electromagnetic interference and consequently compatibility is refer to waves rich in spectral content that produce bad operation in electrical/electronics devices. The subject is known since early day of radio and telegraph communication and today it recognize in two, conducted and radiated, but both division are related.

The analogue signals generated by the Liquid Argon Detector of the ATLAS experiment are processed by frontend crates that are exposed to high levels of radiation and magnetic field. The amount of power required by these front-end crates imposes the presence of a power supply in its vicinity [1].

As the magnetic field limits the use of power transformers, a front-end power supply based on modern $5 \mathrm{~kW}$ DC/DC converters was chosen [2]. They are powered from $\mathrm{AC} /$ DC converters [3] in a control room located 100 meter away of the detector. A DC voltage of $280 \mathrm{~V}$ links both units at a nominal current of $16 \mathrm{~A}$ was selected such that it minimizes the losses in the cable, while it allows the radiation tolerance of the front-end converters.

\footnotetext{
1 Organización Europea de Estudios Nucleares (CERN). CH-1211 Geneva 23, Switzerland.

2 Brookhaven National Laboratory (BNL). New York 11973-5000, USA.

3 Departamento de Electrónica. Universidad Técnica Federico Santa María. Av. España 1680. Valparaíso, Chile. E-mail: jpo@elo.utfsm.cl
} 
The DC powering system faces several electromagnetic compatibility issues that are specific to this configuration:

- Stability of the power link.

- Common mode and differential mode noise.

- EMI emissions of the power cable.

\section{STABILITY OF THE DC POWER LINK}

The AC/DC converter is modelled with a transfer function $F_{l}(s)$. The front-end power supply is made of 27 power modules in parallel with the input and 7 separate output voltages which can be loaded independently. For simplification it is modelled with a transfer function $F_{2}(s)$. Both transfer functions are intrinsically stable. When chained together with a cable of impedance $Z_{S}$ (figure 1), the combination of both transfer functions involves the ratio between the sum of the output impedance $\left(\mathrm{Z}_{01}\right)$ of the AC/DC converter and the impedance of the cable, and the input impedance of the DC/DC converter (1).

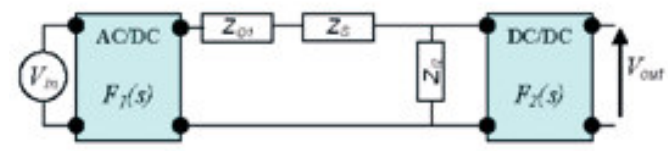

Figure 1. Power conversion model.

$$
\frac{V_{\text {out }}}{V_{\text {in }}}=\frac{\boldsymbol{F}_{1} \cdot \boldsymbol{F}_{2}}{1+\frac{\boldsymbol{Z}_{\boldsymbol{O} 1}+\boldsymbol{Z}_{S}}{\boldsymbol{Z}_{\boldsymbol{I} 2}}}=\frac{\boldsymbol{F}_{1} \cdot \boldsymbol{F}_{2}}{1+\boldsymbol{T}}
$$

To guarantee the stability of the power conversion system, the term $1+T$ to be must be different of zero for all frequencies [4-6].

The input impedance of the front-end DC/DC converter includes a negative resistance defined by the constant power that is delivered to the load (2) [7]. This negative resistance dominates at very low frequencies, and can cause the term $1+\mathrm{T}$ to be equal to zero.

$$
r_{n}=-\frac{V_{\text {load }}}{I_{\text {load }}}
$$

If the output impedance of the primary converter is made much smaller than the negative resistance $r_{n}$ at low frequency, that stability is unconditionally maintained.
This is achieved by means of large decoupling capacitors on the AC/DC converter output [8].

However, the power distribution of the Liquid Argon Detector [10] requires a long power cable, that is characterized by a series resistance and by a series inductance. For increasing frequencies, the resulting impedance soon dominates the $\mathrm{AC} / \mathrm{DC}$ converter output impedance $Z_{O I}$. The decoupling capacitors are not sufficient anymore to insure the stability, and a more detailed analysis is required.

$Z_{O 1}$ is easily determined by measuring the AC/DC converter output decoupling capacitor frequency properties without powering the converter. $Z_{S}$ is easily measured on the cable with a LCR meter. The measurement of $Z_{I 2}$ must be done under power at nominal load to resolve the negative resistance $r_{n}$. A reference AC current is added to the DC current with a bulk injection probe or an inline transformer. The developed voltage on the input of the DC/DC converter is measured with an oscilloscope (figure 2). The amplitude (figure 3 ) and the phase for each impedance is then computed. The phase of $Z_{I 2}$ (figure 4) tends to -180 at very low frequencies because of the negative resistance of the converter. However below 4 $\mathrm{kHz}, Z_{O I}+Z_{S}$ remains smaller than $Z_{I 2}$, and the stability is insured even in presence of the dominant negative resistance.

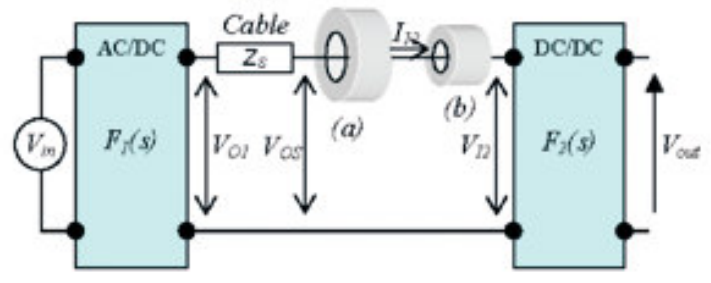

Figure 2. Impedance test setup using an injection probe (a) and a current monitoring probe (b).

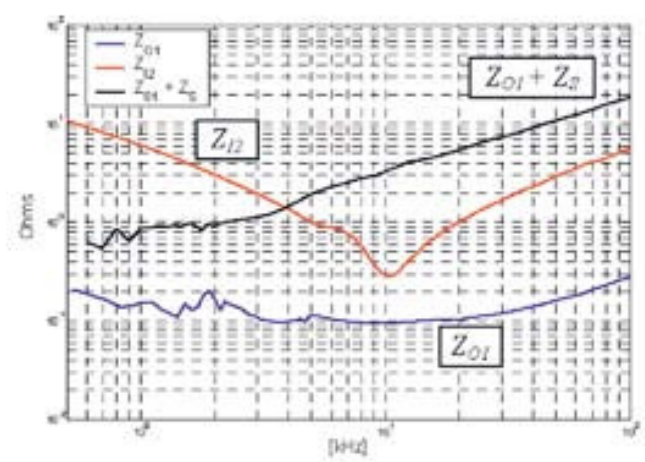

Figure 3. Cable, input and output impedance measurements. 
Alternatively, the stability condition can be evaluated by plotting the ratio $V_{O S} / V_{I 2}$ into a Nyquist chart (figure 5). For increasing frequencies and different load conditions, the plotted curve does not enclose the $(-1,0)$ point and the system is therefore stable.

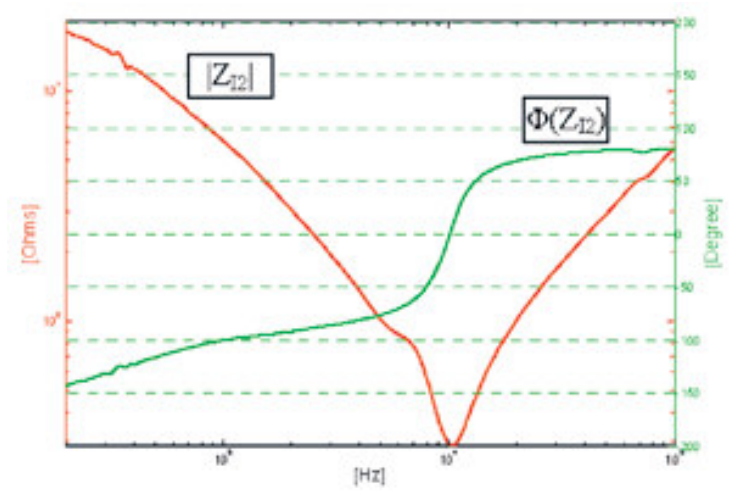

Figure 4. Magnitude and phase of the impedance $Z_{12}$.

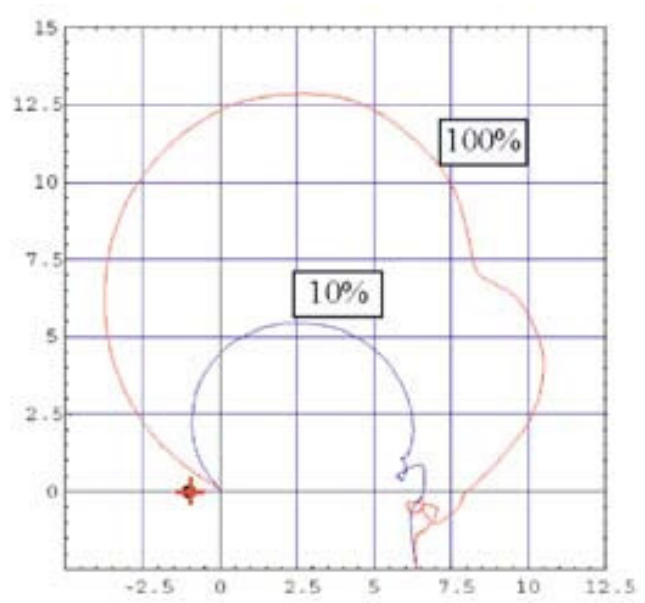

Figure 5. Nyquist chart at $10 \%$ (blue) and $100 \%$ (red) loads.

\section{NOISE PROPAGATION ALONG THE LINK}

The common mode currents in DC power links are identified as the major sources of interferences for the front-end systems. The most critical couplings occur in the near field region between cables that share a common cable tray over long distances $[12,9]$.

The amount of interferences emitted by the power cable over its entire length must stay under a limit at nominal conditions (table 1) for compatibility with the operation of the front-end electronics.
Table 1. ATLAS conducted EMI emission limits.

\begin{tabular}{|l|c|c|}
\hline Range & $9 \mathbf{~ k H z}$ to $\mathbf{5 0 0} \mathbf{~ k H z}$ & $\mathbf{5 0 0} \mathbf{k H z}$ to $\mathbf{1 0 0} \mathbf{~ M H z}$ \\
\hline Limit & $45 \mathrm{~dB} \mu \mathrm{A}$ & $39 \mathrm{~dB} \boldsymbol{\mu A}$ \\
\hline
\end{tabular}

The AC/DC converter emits through the power cable both common and differential mode noise currents. The common mode current returns through the least impedance path, that is the shield of the cable and the protective earth conductor [13]. The long link is modelled as a multiconductor transmission line (MTL) (figure 6) [11].

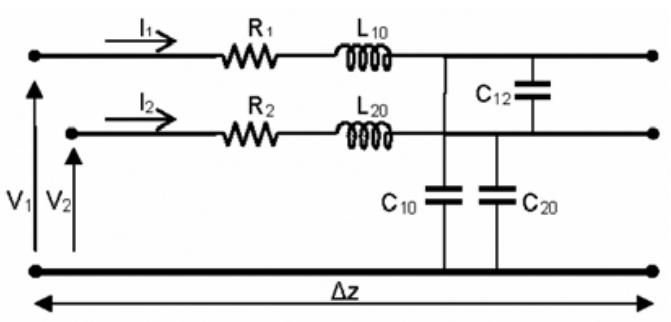

Figure 6. Multiconductor transmission line model for the power cable.

$$
\begin{aligned}
& \frac{\partial}{\partial z} V(z, t)=-R I(z, t)-L \frac{\partial}{\partial t} I(z, t) \\
& \frac{\partial}{\partial z} I(z, t)=-G V(z, t)-C \frac{\partial}{\partial t} V(z, t)
\end{aligned}
$$

The solution of the MTL equations (3) y (4) shows that, as it propagates along the line, the common and differential mode noise currents get amplified or attenuated at resonance frequencies determined by the cable physical properties and by the load [13]. For a known cable, the solution can be computed numerically [9]. Here a direct measurement of the transfer functions was performed on the cable. The amplified common mode current at the load should not exceed the limits applied in ATLAS (The conducted emission limits as applied in ATLAS are obtained from the voltage limits established in the CISPR11 IEC standard [16] and assuming a standard load of $50 \mathrm{ohms}$ ). The common mode transfer function of the cable (5) was measured at loads of $30 \Omega$ and 217 $\Omega$. A reference common mode current is injected into a cable shorted at the source and monitored on both ends (figure 7). The cable is terminated in a resistive load. For strong loads, a common mode amplification greater than $20 \mathrm{~dB}$ occurs around $1.5 \mathrm{MHz}$, while for light loads the effect is almost negligible (figure 8). Therefore, the common mode current emitted by the AC/DC converter must not exceed $19 \mathrm{~dB} \mu \mathrm{A}$ at $1.5 \mathrm{MHz}$. 


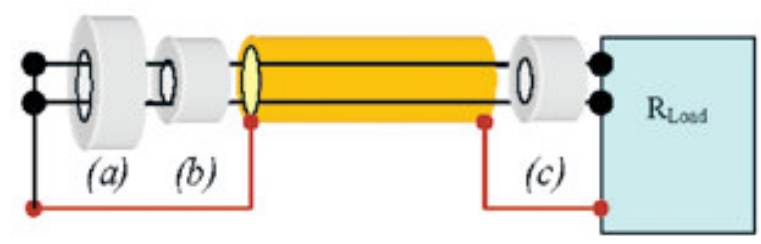

Figure 7. Common mode transfer function measurement setup, with one injection probe (a) and two current probes (b and $\mathrm{c})$.

$$
H_{I_{C M}}=\frac{I_{C M_{\text {FarEnd }}}}{I_{C M_{\text {NearEnd }}}}
$$

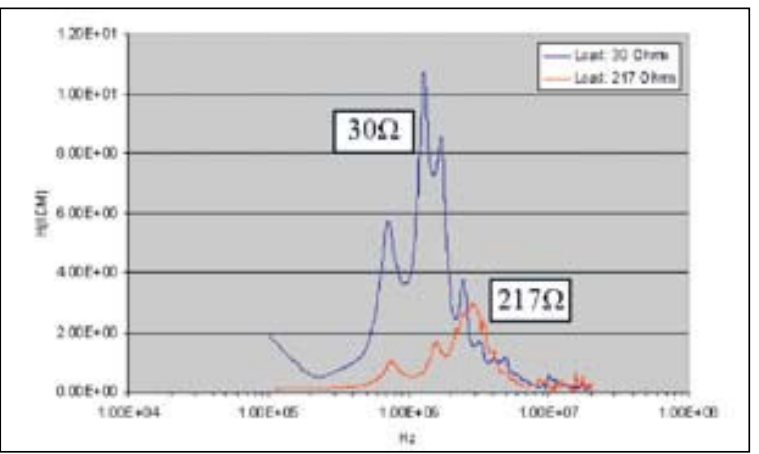

Figure 8. Common mode current transfer function.

The common mode current is also partly converted into differential mode current at the load (ripple) [13]. The transfer function (6) was measured for the same loads, showing a strong common mode to differential mode conversion gain of $30 \mathrm{~dB}$ for light loads at $100 \mathrm{kHz}$. However, at nominal load, the gain is negligible, and no particular constrain for the AC/DC converter is required (figure 9).

$$
H_{I C M \rightarrow D M}=\frac{I_{D M_{\text {FarEnd }}}}{I_{C M_{\text {NearEnd }}}}
$$

A power supply that complies with the ATLAS emission limits on its output, but with very tight margin, will exceed these limits on the front-end side because of the noise amplification effect if the cable is long. The measurement of the noise propagation properties of the power cable is essential to identify the critical frequencies and set more demanding limits in a given frequency range to maintain a reasonable level of EMI emissions close to the frontend electronics. In the case of the Liquid Argon power supplies, the EMI emission limit must be reinforced such that the common mode current does not exceed $19 \mathrm{~dB} \mu \mathrm{A}$ from $0.5 \mathrm{MHz}$ to $4 \mathrm{MHz}$.

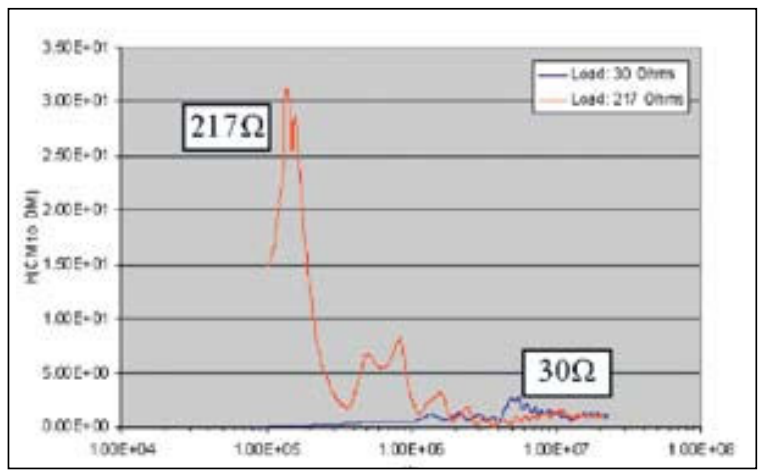

Figure 9. Common mode to differential mode transfer function.

\section{EMI EMISSIONS OF THE DC POWER LINK}

Both front-end and back end power converters are a source of common mode and differential mode noise along the cable. Because the power propagates as a low impedance wave along the cable, it is identified as a mainly inductive source of noise in the near field region (within the cable tray) [12].

The differential mode noise, known as ripple, is caused by the filter of back end converter, and by the frontend switching device. It is a source of electromagnetic interferences at low frequencies [11].

The common mode noise is mainly contributed by the switching devices of both converters. As it returns through a path that sits outside of the differential mode circuit, known as ground, it is a potential source of strong EMI emission if the ground path is not well defined [14]. The common mode noise is the dominant source of EMI emissions by several orders of magnitude when compared to the differential mode noise [12].

In sake of a healthy electromagnetic environment of the experiment, the EMI emissions caused by CM and DM noise must be minimized. The EMI emissions contributed by the AC/DC converter for different grounding schemes were measured using a resistive load of $30 \Omega$ in order to recommend the configuration that leads to the lowest EMI emissions in the ATLAS experimental area.

\section{Common mode current test setup}

The test setup (figure 10) allows to monitor the common mode current on the near end and on the far end of the 100 meter long cable. The current is measured by means of a current probe connected to an EMI receiver, from $9 \mathrm{kHz}$ to $100 \mathrm{MHz}$. The shield can be grounded to the enclosures 
on both ends, and the power return is grounded to the case of the AC/DC converter for safety. The converter itself is grounded to the protective earth of the input mains.

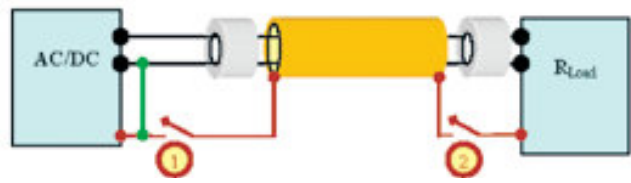

Figure 10. Common mode current setup, with shield grounding switches (1) and (2), and power return earthed.

The comparison is focused on the effect of grounding the shield on the AC/DC converter or on both ends (figure 11).

The common mode current delivered by the AC/DC converter remains below the ATLAS limit, and in the critical frequency range identified previously the level is contained below $20 \mathrm{~dB} \mu \mathrm{A}$ as required. On the side of the load, a clear attenuation is observed, except around 1.5 $\mathrm{MHz}$ where some peaks are amplified. The largest current is achieved on the front-end side when the shield is grounded on both ends.
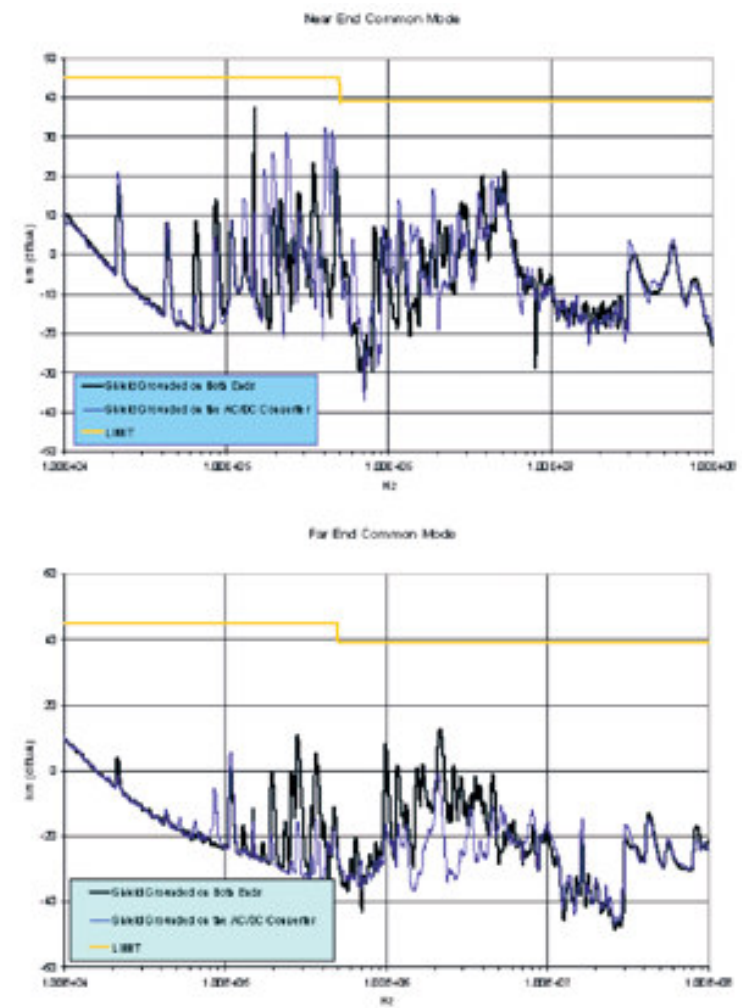

Figure 11. Back end and front-end common mode currents.

\section{EMI emissions}

The EMI emissions are measured with an EMI receiver and a current probe placed around the shield (figure 12), on both ends of the cable (figure 13). If the shield is grounded on both sides, the common mode current returns through it, resulting in a largely reduced EMI emission. The achieved level of $10 \mathrm{~dB} \mu \mathrm{A}$ is more than $30 \mathrm{~dB}$ below the limit and represents a negligible source of interferences for the neighbouring cables.

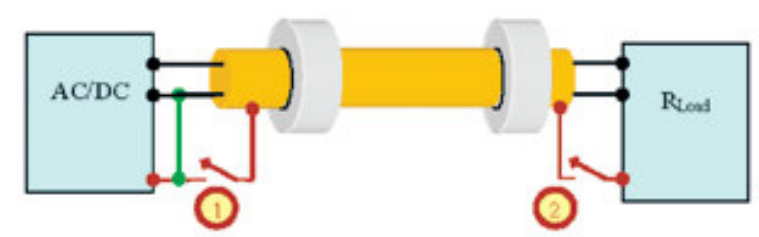

Figure 12. EMI emissions test setup.

The common mode current and the EMI emissions were measured in the ATLAS experimental area as well (figure 14). The resistive load was replaced by the frontend DC/DC converter loaded with a front-end crate, at a nominal load of $3.5 \mathrm{~kW}$. The front-end converter and the dynamic load are additional sources of noise. The near end common mode current is now increased and it largely exceeds the ATLAS limit. However, the shield reduces the EMI emissions [15] below the limit excepting at 100 $\mathrm{kHz}$, with a peak of $600 \mu \mathrm{A}$.
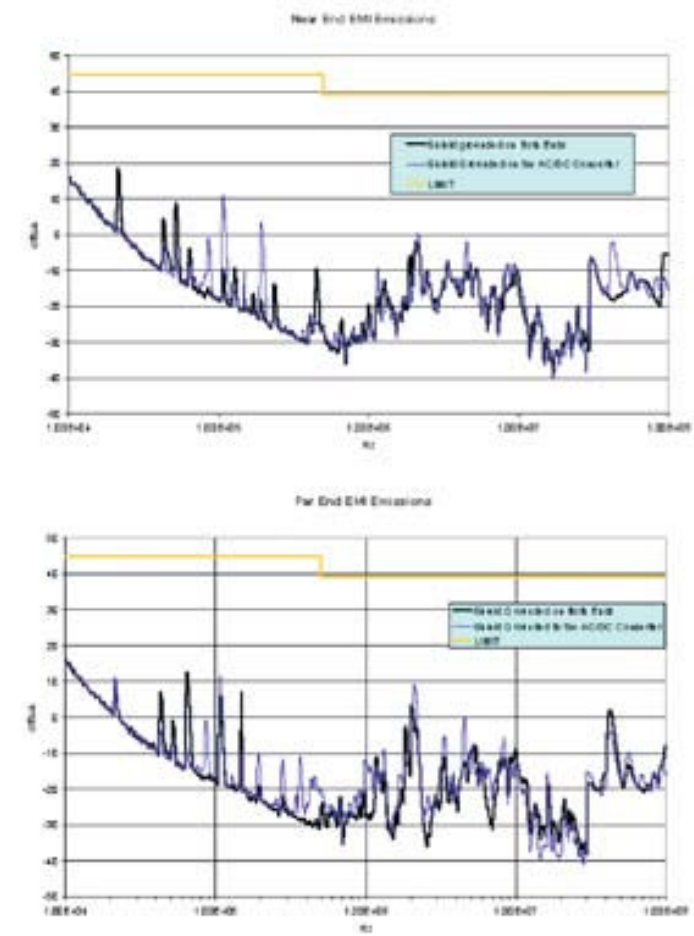

Figure 13. Back end and front-end EMI emissions. 


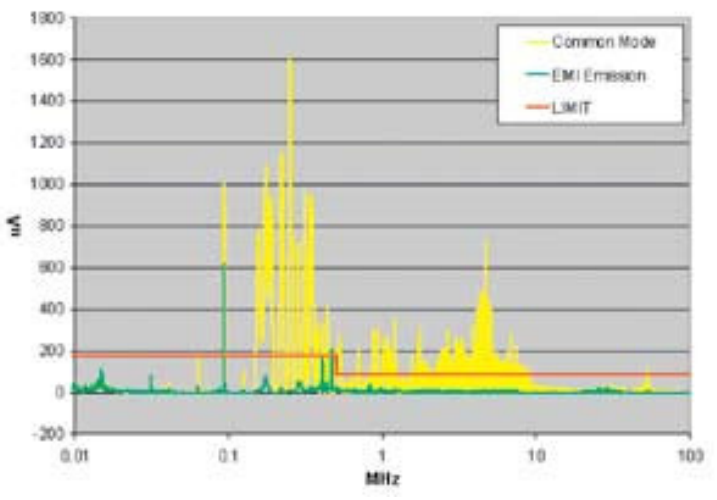

Figure 14. Common mode and EMI emissions measured on the experimental area.

\section{Grounding of the return line}

The return line must be bonded to earth on the AC/DC converter to comply with mandatory safety requirements. The impact of such grounding connection on the EMI emissions was measured (figure 15). The lowest EMI level is achieved with the shield connected on both ends, while a floating return results in more than $30 \mathrm{~dB}$ increase of EMI emissions on the front-end side. Therefore, the grounding of the return line is an effective way to reduce the noise emissions in the experimental area [14].

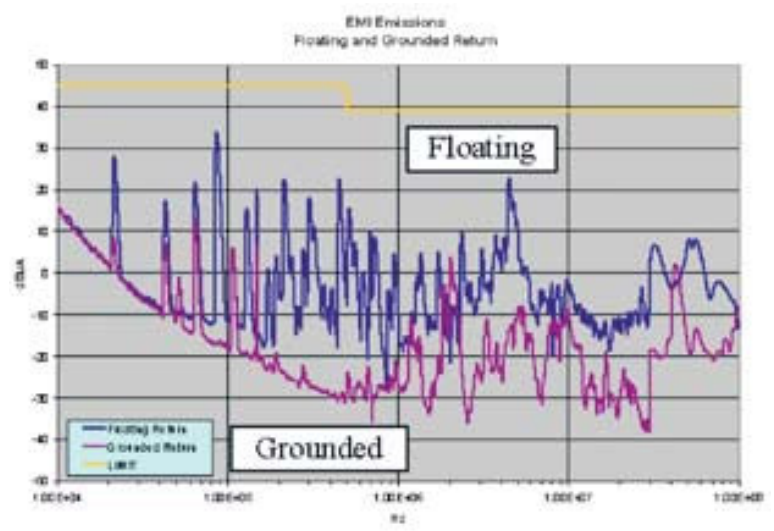

Figure 15. Effect of floating the power return on the EMI emissions.

\section{CONCLUSIONS}

The DC power link used to feed the front-end electronics of the Liquid Argon Calorimeter brings specific electromagnetic compatibility issues that can represent a threatening EMI source for the experiment.
The negative resistance of the DC/DC converter input impedance is a potential source of instability for the back end converter. The measurement and analysis of the input and output impedances allowed the identification of the frequency range up to $1 \mathrm{kHz}$ where the negative resistance becomes a hazard. Large decoupling capacitors on the output of the bulk power converter keep the output impedance one order of magnitude below the DC/DC converter input impedance, insuring in this way the stability.

The measurement of the common mode current transfer function of the long power cable allows the identification of a resonance effect with a gain of $10 \mathrm{~dB}$ around $1.5 \mathrm{MHz}$ at nominal load. Therefore the bulk power converter must provide $20 \mathrm{~dB}$ of margin with respect to the ATLAS EMI emission limits in that range.

The measurement of the common mode current emitted by the AC/DC converter into a resistive load reveals sufficient margin with respect to the ATLAS limits independently of the grounding of the shield on one end or on both ends.

The inclusion of the shield current shows that it is a very effective return path for the common mode current. Grounding the shield on both ends appears as the most effective configuration, with EMI emissions below $10 \mathrm{~dB} \mu \mathrm{A}$. The front-end converter is the major source of common mode current on the link, but it is effectively contained by the shield. In this configuration, the only critical source of EMI is found at $100 \mathrm{kHz}$ with a current amplitude of $600 \mu \mathrm{A}$. The effect of grounding the power return was also measured. Floating the power return would increase the EMI emissions by up to $50 \mathrm{~dB}$. Proper decoupling of the $\mathrm{AC} / \mathrm{DC}$ converter together with proper grounding of the shield and of the return line allows the implementation of a stable and low noise high power distribution system.

\section{ACKNOWLEDGEMENTS}

The authors gratefully acknowledge the support provided by Millennium Nucleus in Industrial Electronics and Mechatronics granted by Mideplan-Chile and the support given by the Fondef projet $\mathrm{N}^{\circ}$ D04I1392 and the Universidad Técnica Federico Santa María.

\section{REFERENCES}

[1] F. Arteche. "The Front-End Board for the ATLAS Liquid Argon Calorimeter". 4th Workshop on Electronics for LHC Experiments. Rome, Italy. 1998. 
[2] Modular Devices Incorporated, DC/DC Converters. URLs: http://www.mdipower.com

[3] OCEM, AC/DC Converters. URLs: http://www. ocem.it

[4] B.H. Cho, F.C.Y Lee. "Modeling and analysis of spacecraft power systems". IEEE Transactions on Power Electronics. Vol. 3 No 1, pp. 44-54. 1988.

[5] C.M. Wildrick, F.C. Lee, B.H. Cho, B. Choi. "A Method of Defining the Load Impedance Specification for A Stable Distributed Power System". IEEE Transactions on Power Electronics, pp. 280-285. Vol. $10 \mathrm{~N}^{\circ}$ 3. 1995.

[6] L.R. Lewis, B.H. Cho, F.C. Lee, B.A. Carpenter, Modeling. "Analysis and design of distributed power systems". Power Electronics Specialists Conference. Vol. 1, pp. 152-159. 1989.

[7] F. Arteche. "EMI Filter Design and Stability Assessment of a DC Voltage Distribution Based on Switching Converters". 7th Workshop on Electronics for LHC Experiments. Stockholm, Sweden. 2001.

[8] D.M. Mitchell. "Power Line Filter Design Considerations for DC-DC Converters". IEEE Industry Applications Magazine. Vol. $5 \mathrm{~N}^{\circ} 6$, pp. 16-26. 1999.

[9] S.A. Pignari. "Long-Cable Effects on Conducted Emissions Levels". IEEE Transactions on EMC. Vol. $45 \mathrm{~N}^{\circ}$ 1, pp. 43-54. 2003.
[10] C. Rivetta, F. Arteche, F. Szoncso. "A Common $400 \mathrm{~Hz}$ AC Power Supply Distribution System for CMS Front-end Electronics". 8th Workshop on Electronics for LHC Experiments. Colmar, France. 2002.

[11] C.R. Paul. "Introduction to Electromagnetic Compatibility". Second edition. John Wiley Sons Inc, NY. 1992.

[12] G. Blanchot. "Overview of the ATLAS Electromagnetic Compatibility Policy". 10th Workshop on Electronics for LHC Experiments. Boston, USA. 2004.

[13] F.Arteche. "Effects of CM and DM noise propagation in LV distribution cables". 9th Workshop on Electronics for LHC Experiments. Amsterdam, Netherlands. 2003.

[14] F. Szoncso, Earthing of High-Energy Physics. 5th Workshop on Electronics for LHC Experiments. USA. 1999.

[15] R. Morrison. "Grounding and Shielding Techniques". Fourth edition. JohnWiley Sons Inc, NY. 1998.

[16] International Standard IEC-CISPR-11, Industrial, Scientific and Medical (ISM) Radio Frequency Equipment-Electromagnetic Disturbance Characteristics-Limits and Methods of Measurement. 2003. 